\title{
Stock and Bond Market Liquidity: A Long-Run Empirical Analysis
}

\author{
Ruslan Y. Goyenko and Andrey D. Ukhov*
}

\begin{abstract}
This paper establishes liquidity linkage between stock and Treasury bond markets. There is a lead-lag relationship between illiquidity of the two markets and bidirectional Granger causality. The effect of stock illiquidity on bond illiquidity is consistent with flight-toquality or flight-to-liquidity episodes. Monetary policy impacts illiquidity. The evidence indicates that bond illiquidity acts as a channel through which monetary policy shocks are transferred into the stock market. These effects are observed across illiquidity of bonds of different maturities and are especially pronounced for illiquidity of short-term maturities. The paper provides evidence of illiquidity integration between stock and bond markets.
\end{abstract}

\section{Introduction}

Liquidity conditions in financial markets have become a subject of active research in recent years. Current studies of the determinants of liquidity movements have evolved in two distinct directions. First, they are mostly restricted to either equity or bond markets. ${ }^{1}$ Second, studies of time-series behavior of liquidity are constrained by short or medium time spans for which high-frequency market microstructure data are available. ${ }^{2}$

\footnotetext{
*Goyenko, ruslan.goyenko@mcgill.ca, Desautels Faculty of Management, McGill University, 1001 Sherbrooke St. West, Montreal, Quebec H3A 1G5, Canada; and Ukhov, a-ukhov@kellogg .northwestern.edu, Kellogg School of Management, Northwestern University, 2001 Sheridan Rd, Evanston, IL 60208. This research was conducted when Ukhov was at Kelley School of Business, Indiana University. We are grateful to Yakov Amihud, Stephen Brown (the editor), Tarun Chordia (the referee), Lawrence Davidson, Adlai Fisher, Michael Fleming, Craig Holden, Christian Lundblad, Michael Piwowar, Duane Seppi, Avanidhar Subrahmanyam, Charles Trzcinka, Akiko Watanabe, and participants of FMA 2005 Chicago meeting and NFA 2006 Montreal meeting for helpful comments and discussions.

${ }^{1}$ For example, see Hasbrouck and Seppi (2001), Huberman and Halka (2001), and Chordia, Roll, and Subrahmanyam (2000), (2001) for equity markets, and Fleming (2003), Huang, Cai, and Wang (2002), Brandt and Kavajecz (2004), Fleming and Remolona (1999), and Balduzzi, Elton, and Green (2001) for U.S. Treasury bond markets. See Chordia, Sarkar, and Subrahmanyam (2005) for joint study.

${ }^{2}$ For example, Chordia, Roll, and Subrahmanyam (2001) report time-series properties and determinants of daily stock market liquidity and trading activity over an 11-year period (1988 though
} 
This paper contributes on both dimensions. We analyze the joint dynamics of stock and Treasury bond market illiquidity over a long time span. We find that stock and Treasury bond markets are linked not only via volatility (Fleming, Kirby, and Ostdiek (1998)) but via illiquidity as well. In particular, vector autoregression analysis shows that there is a strong lead-lag relationship and bidirectional Granger causality between illiquidity of the two markets. Positive shock to stock illiquidity decreases bond illiquidity, which is consistent with flight-to-quality or flight-to-liquidity episodes. In contrast, positive shock to bond illiquidity increases stock illiquidity. Illiquidity conditions in the two major markets affect each other.

We show that this effect is related to a difference in the nature of equity and bond market illiquidity. In particular, we find that bond market illiquidity is mostly affected without a lag by monetary policy variables, while stock illiquidity reacts to a monetary shock with a lag. Illiquidity of short-term bonds is first to react to changes in monetary policy variables. In analyzing joint dynamics of monetary variables, stock and bond market variables, and illiquidity of both markets, we show that illiquidity increases in response to monetary policy tightening. ${ }^{3}$ We also find that bond illiquidity plays an important role as a channel for transmitting monetary shocks into the stock market. These results are new to the literature. They establish the illiquidity spillover between these markets and the mutual impact of illiquidity conditions in these two asset classes. The results also show the connection between macroeconomic variables and financial market illiquidity and demonstrate the important role of bond illiquidity as a channel for transmitting the effects of monetary policy into the equity market.

Our study asks questions about the economic relationship between illiquidity in these markets. Uncovering the connection depends on a sample period long enough to subsume a variety of economic events. ${ }^{4}$ As Shiller and Perron (1985) and Shiller (1989) show, increasing the number of observations in studies of economic and financial data by sampling more frequently while leaving the span in years of data unchanged may not increase the power of tests very much. Recognizing that the power of our tests depends more on the span of the data rather than the number of observations, we consider a longer horizon that spans the data from July 1962 to December 2003.

Another important feature of our study is that it is the first paper to consider bond illiquidity of different maturities: short, medium, and long term. We analyze the illiquidity of each maturity class separately because flights into or out

1998). Chordia, Sarkar, and Subrahmanyam (2005) study the joint dynamics of liquidity and trading activity of stock and U.S. Treasury bond markets over daily data for the period from June 17, 1991 to December 31, 1998.

${ }^{3}$ Guided by previous literature (Chordia, Roll, and Subrahmanyam (2001), Chordia, Sarkar, and Subrahmanyam (2005)), we also use returns and volatility of returns as the candidates for common determinants of illiquidity.

${ }^{4}$ If the time series $y_{t}$ and $x_{t}$ make long, relatively slow movements through time (a common feature for economic and financial data), then we will need a long time series (spanning many years) before we can measure the true joint tendencies of the two variables. Getting many observations by sampling frequently (say, through weekly or even daily observations) will not give us much power to measure the joint relationship between the two time series if the total time span in which our data are contained is only a few years long. Shiller (1989) stresses the importance of this argument. 
of the bond market may not target specific maturity ranges (Beber, Brandt, and Kavajecz (2009)). Thus, it is difficult to hypothesize which bond maturity is most relevant when studying illiquidity relationships in the stock and bond markets. We therefore adopt a flexible approach and study three maturity classes separately. We find that cross-market illiquidity spillover occurs along the whole yield curve (i.e., across maturities of all ranges). The effect is especially pronounced for illiquidity of short-term maturities, the most liquid asset class.

Our finding of illiquidity spillover across markets is closely connected with the literature that considers illiquidity as a risk factor in each market. If illiquidity is a systematic factor that investors take into account in their investment decisions, then portfolio allocations can be expected to change to take illiquidity conditions into account. In this case, we can also expect illiquidity to have an effect across asset classes. A change in illiquidity of one asset class will affect its relative attractiveness. An illiquidity shock in the stock (bond) market will result in trading and will affect demand in both markets. The change in demand will impact illiquidity in the bond (stock) market. The notion of illiquidity as a systematic risk factor in this setting leads to the interdependence in illiquidity. We find support for this hypothesis, and this finding can be interpreted as additional support for the view of illiquidity as a risk factor.

Our paper substantially contributes to the findings of Chordia, Sarkar, and Subrahmanyam (CSS) (2005). CSS report that stock and bond market illiquidity comoves, and they find no evidence of cross-market causation in their sample. We go further and report that stock and bond markets are integrated via illiquidity, and that illiquidity of one market has a predictive power for illiquidity of the other market. CSS analyze illiquidity of 10-year notes only, while we incorporate illiquidity of bonds of different maturities. This allows us to demonstrate the relative importance of each maturity category in causing cross-market illiquidity spillover. During their sample period, CSS cannot draw any conclusions about the predictive effect of monetary policy on illiquidity. We find strong evidence in favor of the predictive power of monetary policy over financial market illiquidity. This finding is fully consistent with our motivation for a long-horizon study. A long span of data in years is needed to capture several monetary shocks, which is necessary to detect this channel.

We measure illiquidity in the Treasury market with relative quoted spreads. This is a standard measure for the Treasury market. ${ }^{5}$ Bond illiquidity is represented by the illiquidity of three different maturities, short-bond illiquidity is illiquidity of T-bills with maturity less than or equal to one year, medium-bond illiquidity is illiquidity of two- to seven-year bonds, and long-bond illiquidity is illiquidity of 10-year notes. For the stock market, the high frequency microstructure data that are used to compute effective and quoted spreads are not available for the whole time period of our analysis. To measure illiquidity in the stock market we therefore employ Amihud's (2002) widely used illiquidity measure.

The rest of the paper is organized as follows. Section II motivates the hypotheses and discusses related literature. Section III describes liquidity measures.

\footnotetext{
${ }^{5}$ Fleming (2003), comparing several liquidity proxies, concludes that quoted spread is the best measure to track changes in Treasury market illiquidity.
} 
Section IV reports the results of vector autoregression analysis. Section V concludes.

\section{Hypotheses and Related Literature}

There are reasons to expect that illiquidity spillover between stock and bond markets exists. ${ }^{6}$ First, there are strong volatility linkages between the two markets (Fleming et al. (1998)), and volatility can affect illiquidity in both markets by changing the inventory risk born by market makers (Ho and Stoll (1983), O'Hara and Oldfield (1986)). Second, trading activity may cause an interaction between stock and bond market illiquidity. A number of asset allocation strategies shift wealth between stock and bond markets (Fox (1999), Swensen (2000)). In times of economic distress investors often rebalance their portfolios toward less risky and more liquid securities. These phenomena are commonly referred to as a flight to quality and a flight to liquidity, respectively. Longstaff (2004) reports a large liquidity premium in Treasury bonds and finds strong evidence that this premium, among other things, is related to changes in flows into equity and money market mutual funds. This indicates that illiquidity is linked with the cross-market trading activity when investors move funds between equities and fixed income securities. Goetzmann and Massa (2002) find that investors move funds in and out of the equity market in response to daily market news and changes in risk. The authors show that fund flows affect prices in equity markets. Agnew and Balduzzi (2005) find that $401(\mathrm{k})$ plan participants rebalance between equities and fixed income instruments at a daily frequency, depending on market news. The resulting flows between stocks and Treasury bonds may cause price pressures and also jointly impact stock and bond illiquidity.

Fund flows may be an important source of illiquidity linkages between the two markets. Motivated by this observation, we analyze three maturity classes (short, medium, and long) in the Treasury market separately, because according to Beber et al. (2009), flights into or out of the bond market do not target specific maturity ranges. It is, therefore, difficult to hypothesize which bond maturity is most relevant when studying illiquidity relationships in the stock and bond market. In fact, Longstaff (2004) documents liquidity premium across all maturities ranging from three month to 30 years, which suggests that all maturities may be relevant for a study of illiquidity. Thus, we adopt a flexible approach and include measures of illiquidity for all three Treasury maturity classes rather than limiting the study to one class.

In addition, by studying illiquidity of the three maturities separately, we retain any differences between flights into and out of the bond market related to the asset characteristics that may be present in the data. For example, during periods with very high demand for liquidity, we can expect higher fund inflows into the short maturities as the most liquid asset class. Similarly, when investors shift out of the bond market, they may first leave more liquid assets, which are easier to

\footnotetext{
${ }^{6} \mathrm{CSS}$ (2005) study joint properties of stock and bond market liquidity, but in their sample (covering 7.5 years of data) they cannot draw any conclusions about cross-market causation or illiquidity spillover.
} 
trade. A common practice of using funds in a money-market brokerage account to purchase equities is an example of such a decision. Beber et al. (2009) find that investors price the transaction cost component both when they enter and exit the bond market. This suggests that illiquidity of short-term bonds may behave differently and contain different information compared to the illiquidity of other maturities. In particular, we expect to observe a stronger illiquidity linkage between illiquidity of stocks and short-term bonds, but we do not expect the linkage to be specific to short-term bonds only.

According to recent studies, illiquidity behaves as a systematic risk factor (Chordia, Roll, and Subrahmanyam (CRS) (2000), Hasbrouck and Seppi (2001), Huberman and Halka (2001), and Amihud (2002)). The evidence comes from studies of the cross section of equity returns (Amihud (2002), Pastor and Stambaugh (2003)), studies of time-series properties of illiquidity in equity (Amihud and Mendelson (1986), (1989), Brennan and Subrahmanyam (1996), Amihud (2002), and Jones (2002)), and studies of the U.S. Treasury bond markets (Amihud and Mendelson (1991), Warga (1992), Boudoukh and Whitelaw (1993), Kamara (1994), Krishnamurthy (2002), and Goldreich, Hanke, and Nath (2005)).

If illiquidity conditions in the two markets represent systematic risk factors that are essentially attributed to the same nature (market frictions), then we may expect illiquidity in these two markets to influence each other. That is, a shock to stock illiquidity may be expected to affect bond illiquidity, and vice versa. This suggests that illiquidity in the stock and bond markets not only covaries, but also that illiquidity conditions in the two markets have an effect on one another. The mutual effect of illiquidity in the two markets is an important new hypothesis that we test in this paper.

Trading activity is one channel for interdependence in stock and bond illiquidity. If there are leads and lags in trading activity in response to systematic wealth or informational shocks, then trading activity in one market may predict trading activity, and, in turn, illiquidity in another. As a systematic risk factor, illiquidity of each market affects the consumption-portfolio problem and trading activity across both markets. ${ }^{7}$ An illiquidity shock in the stock (bond) market will result in trading and will affect demand in both markets. The change in demand will impact illiquidity in the bond (stock) market. The notion of illiquidity as a systematic risk factor in this setting leads to interdependence in illiquidity, a hypothesis that we seek to explore.

Illiquidity spillover may also be closely related to a lead-lag relationship between illiquidity of the two markets. Thus, if macro or monetary shocks to illiquidity become reflected in one market before the other, then illiquidity in one market could influence future illiquidity in the other. This, in turn, may indicate an indirect effect of monetary policy on illiquidity of one asset class via the illiquidity of the other asset class. Empirically, there is overwhelming evidence highlighting the effect of macroeconomic news on illiquidity of Treasury bonds (Fleming and Remolona (1997), (1999), Balduzzi et al. (2001), and Green (2004)). These results have been established for macroeconomic announcements over intraday

\footnotetext{
${ }^{7}$ For example, within a context of an intertemporal CAPM, investors trade to hedge their exposure to the changes in all state variables or systematic risk factors (Ingersoll (1987)).
} 
patterns. The nature of the relationship between illiquidity and monetary policy over a longer time span, and under a variety of economic conditions, has not been explored yet. There are reasons, however, to expect this relationship to be strong. For example, consider the measures of the Federal monetary policy stance. A loose monetary policy may decrease illiquidity and encourage more trading by making margin loan requirements less costly and by enhancing the ability of dealers to finance their positions. Monetary conditions may also affect asset prices through their effect on volatility (Harvey and Huang (2002)) and interest rates. There also could be reverse causality because increased illiquidity could, in turn, spur the Federal Reserve to soften its monetary stance.

Monetary policy may be expected to have a different impact on stock and bond illiquidity due to a fundamental difference between the two asset classes. Stock prices depend on both uncertain cash flows and the discount rate, while bond prices (for which cash flows are fixed) depend only on the discount rate. The reported announcement effects in the bond market suggest that the movements in this market are related to information arrival (Green (2004)). The information affecting discount rates is supplied by the monetary policy, and the behavior of Treasury bond prices is closely tied to the monetary policy. For the stock market, the movements depend on information on either cash flow, discount rate, or both. McQueen and Roley (1993), for example, find that stock prices vary significantly in their response to macroeconomic announcements depending on the state of the economy. Changes in expected cash flows are the important source of the variation in response. These differences between stock and bond markets may be reflected in the different reaction of the trading activity and illiquidity to monetary policy shocks. Whether the response in illiquidity to monetary policy shocks is different across the two asset classes is an empirical question that we intend to explore.

Other factors, such as unexpected productivity declines and excessive inflationary pressures, are likely to influence illiquidity indirectly by inducing fund outflows, price declines, and increased volatility, exacerbating inventory risk. Inflation shocks can affect illiquidity through an increase in inventory holding and order processing costs. When productivity is high, the return on risky assets increases and investments in these assets are more attractive. This leads to increases in prices and liquidity of the risky assets (Eisfeldt (2004)). Consequently, we would expect cash outflows from bond markets and decrease in bond liquidity.

\section{Liquidity Measures}

\section{A. Bond Illiquidity}

We measure illiquidity in the Treasury market with relative quoted spreads. This is a standard measure for the Treasury market. The simple bid-ask spread, based on widely available data, is highly correlated with price impact, which otherwise is difficult to estimate on a timely basis due to data limitations (Fleming (2003)). The quoted bid and ask prices are from CRSP daily Treasury Quotes file from June 1962 to December 2003. The file includes Treasury fixed income securities of 3 and 6 months and 1, 2, 3, 5, 7, 10, 20, and 30 years to 
maturity. ${ }^{8}$ We delete the first month(s) of trading, when a security is on-the-run, since many trades at this time are due to interdealer trading, and an illiquidity premium has been documented for off-the-run issues (Amihud and Mendelson (1991)). We also delete the last month of trading, since this is the maturity month. The quoted spread for Treasury bond market is computed as

$$
\mathrm{QS}=\frac{\mathrm{ASK}-\mathrm{BID}}{\frac{1}{2}(\mathrm{ASK}+\mathrm{BID})},
$$

where ASK and BID are quoted ask and bid prices for a particular day (using only two-sided quotes for the calculation). The monthly average spread is computed for each security and then equally weighted across different assets for each month.

We use three bond illiquidity series and study three maturity classes separately. The first is the short-term illiquidity, computed for T-bills with maturity less than or equal to one year. The second is illiquidity of the medium-maturity assets, obtained from the quotes on two- to seven-year bonds. The third is illiquidity of the 10-year note, a traditional benchmark used to measure liquidity in the Treasury bond market by CSS (2005).

\section{B. Stock Illiquidity}

An important determinant of our choice of the liquidity measure is the long time period of our study. The high frequency microstructure data that are used to compute effective and quoted spreads are not available for the whole time period of our analysis. To measure illiquidity in the stock market, we therefore use Amihud's (2002) illiquidity measure. Amihud (2002) and Hasbrouck (2006) argue that illiquidity is a good measure of the liquidity environment in the stock market.

As defined by Amihud (2002), the illiquidity of stock $i$ in month $t$ is

$$
\operatorname{ILLIQ}_{t}^{i}=\frac{1}{\mathrm{DAYS}_{t}^{i}} \sum_{d=1}^{\mathrm{DAYS}_{t}^{i}} \frac{\left|R_{t d}^{i}\right|}{V_{t d}^{i}},
$$

where $R_{t d}^{i}$ and $V_{t d}^{i}$ are, respectively, the return and dollar volume (in millions) on day $d$ in month $t$, and DAYS $t_{t}^{i}$ is the number of valid observation days in month $t$ for stock $i$. This measure has the following intuition. A stock is illiquid (i.e., has a high value of $\operatorname{ILLIQ}_{t}^{i}$ ) if the stock price moves a lot in response to little volume. ${ }^{9}$ For convenience, the ratio is multiplied by $10^{5}$.

\section{Vector Autoregression Analysis}

The goal of our analysis is to explore variables that jointly move stock and bond illiquidity. Earlier studies suggest that returns and volatility of returns are

\footnotetext{
${ }^{8}$ The Treasury eliminated regular issuance of three-year notes in 1998 and reduced the issuance of five-year notes from monthly to quarterly. The issuance of 30 -year bonds was terminated in February 2002.

${ }^{9} \mathrm{ILLIQ}_{t}^{i}$ is computed for NYSE/AMEX common stocks with at least 15 observations on return and volume during the month $t$.
} 
important drivers of illiquidity (Amihud and Mendelson (1986), Benston and Hagerman (1974)). More recent studies find that returns affect illiquidity in the stock market (CRS (2001), CSS (2005)), and that there exists a cross-market dynamic flowing from volatility to illiquidity between stock and bond markets (CSS). Motivated by these observations, we analyze the relationship between stock and bond market illiquidity, controlling for returns and volatility of returns of both markets.

The data and notation are as follows: RETS is the return on CRSP NYSE/ AMEX value-weighted market index; RETB is the return on 10-year Treasury note; and VOLS and VOLB are the volatility of corresponding returns, computed as the standard deviation of daily returns over each month. Amihud's (2002) illiquidity is the measure of stock illiquidity. Bond illiquidity is represented by the illiquidity of three different maturities: short-bond illiquidity is the illiquidity of T-bills with maturity less than or equal to one year, medium-bond illiquidity is the illiquidity of two- to seven-year bonds, and long-bond illiquidity is the illiquidity of 10-year notes. All data cover the period from July 1962 to December 2003.

Table 1 presents summary statistics for illiquidity time series. As expected, bond illiquidity is always lower than illiquidity of the stock market. Across different maturities, short-term bills are more liquid than medium maturity bonds, which are more liquid than long-term notes.

\section{TABLE 1}

Descriptive Statistics for Liquidity Measures

Stock illiquidity is estimated for monthly data from July 1962 to December 2003 (498 months) for all NYSE/AMEX firms (common stocks, share code 10 or 11) with Amihud's (2002) illiquidity measure. Bond illiquidity is computed from quoted spreads for the same time period across bonds of different maturities. Short-Bond Illiquidity is illiquidity of T-bills, MediumBond Illiquidity is illiquidity of two- to seven-year bonds, and Long-Bond Illiquidity is illiquidity of 10-year notes.

\begin{tabular}{|c|c|c|c|c|}
\hline & Stock Illiquidity & Short-Bond Illiquidity $^{a}$ & Medium-Bond Illiquiditya & Long-Bond Illiquidity $^{a}$ \\
\hline Average & 0.340 & 0.029 & 0.125 & 0.218 \\
\hline Std. dev. & 0.349 & 0.025 & 0.067 & 0.228 \\
\hline Min & 0.026 & 0.003 & 0.030 & 0.028 \\
\hline Median & 0.218 & 0.019 & 0.121 & 0.153 \\
\hline Max & 2.713 & 0.129 & 0.306 & 1.093 \\
\hline
\end{tabular}

a Bond illiquidity is multiplied by 100 .

Given that there are reasons to expect cross-market effects and bidirectional causalities, as in CSS, we adopt an eight-equation vector autoregression specification that incorporates eight variables: three for the stock market (illiquidity, return, and volatility) and five for the bond market (return, volatility, and illiquidity of short, medium, and long maturities). Therefore, consider the following system:

$$
\begin{aligned}
X_{t} & =\sum_{j=1}^{K} a_{1 j} X_{t-j}+\sum_{j=1}^{K} b_{1 j} Y_{t-j}+u_{t} \quad \text { and } \\
Y_{t} & =\sum_{j=1}^{K} a_{2 j} X_{t-j}+\sum_{j=1}^{K} b_{2 j} Y_{t-j}+v_{t},
\end{aligned}
$$


where $X(Y)$ is a vector that represents illiquidity, returns, and volatility in the stock (bond) markets. The number of lags, $K$, in equations (1) and (2) is chosen on the basis of the AIC and Schwarz Bayesian Information Criterion. ${ }^{10}$

\section{A. VAR Estimation Results: Market Variables}

The correlation matrix between VAR endogenous variables is presented in Table 2. Correlation between volatility across markets is 0.396 , which supports a strong volatility linkage between stocks and Treasuries (Fleming et al. (1998)). Bond volatility is negatively correlated with stock market illiquidity $(-0.323)$. Stock market volatility is positively correlated with stock market illiquidity. Further, stock market volatility has a positive correlation with illiquidity of long-term bonds (0.09), and negative correlation $(-0.082)$ with illiquidity of medium-term bonds. Illiquidity of medium-term bonds has the lowest correlation with stock market illiquidity (0.114), and illiquidity of long-term bonds has the highest correlation with stock illiquidity (0.611). Bond illiquidity series are highly correlated between themselves but not perfectly. The correlation ranges from 0.586 between medium- and long-term illiquidity to 0.865 between short- and medium-term illiquidity. The correlation structure between variables indicates that while bond illiquidity series comove, they have different dynamic relationships with stock market variables that are dependent on maturity.

TABLE 2

\section{Correlations in State Variables}

Table 2 presents the correlation matrix for the time series of market-wide stock and bond illiquidity, returns, and volatility. Bond illiquidity estimates are based on quoted spreads across bonds of different maturities. Stock illiquidity is measured with Amihud's (2002) illiquidity measure. RET is the market return, and VOL is the return volatility computed as standard deviation of daily returns over each month. The returns used are the 10-year Treasury note return from CRSP Fixed Term indices file for bonds, and the CRSP value-weighted index return for stocks. The suffixes B and S refer to bond and stock variables, respectively. The sample spans the period from July 1962 to December 2003 (498 months).

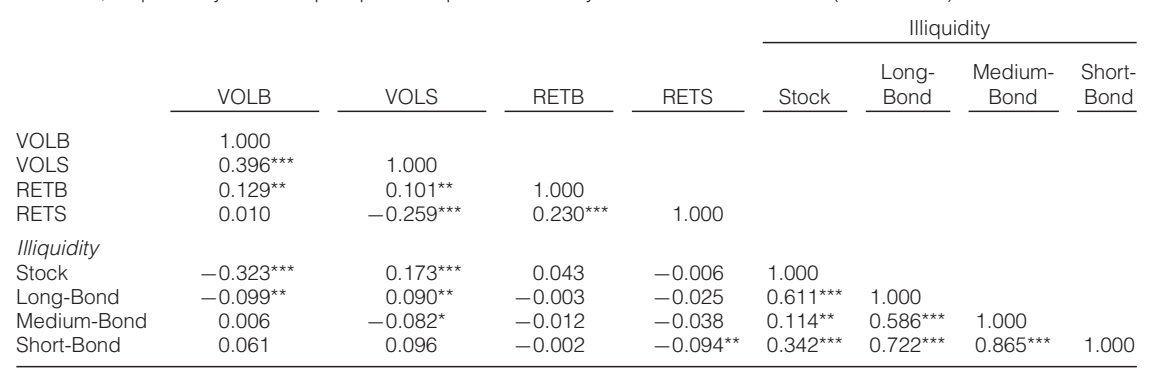

${ }^{* \star \star},{ }^{* *}$, and ${ }^{*}$ denote significance at the $1 \%, 5 \%$, and $10 \%$ levels, respectively.

\footnotetext{
${ }^{10}$ All variables in the VARs are assumed to be stationary. Since the discriminatory power of unit root tests is low (Xiao and Phillips (1999)), we explore the stationarity issue within the VAR system. For example, for VAR(1) representation, $Y_{t}=\Phi Y_{t-1}+\varepsilon_{t}$, the stationarity condition requires that all eigenvalues of the companion matrix $\Phi$ be less then one in absolute value. We conduct this test for each VAR specification and find that the stationarity condition is satisfied. The robustness of standard errors is addressed via bootstrapped confidence intervals. All estimates reported below fall into $95 \%$ bootstrap confidence bands.
} 
Table 3 reports Granger-causality tests between the endogenous variables in the VAR. For the null hypothesis that variable $i$ does not Granger cause variable $j$, we test whether the lag coefficients of $i$ are jointly zero when $j$ is the dependent variable in the VAR. The cell associated with the $i$ th row variable and the $j$ th column variable shows the $\chi^{2}$ statistics and corresponding $p$-values in parentheses.

\section{TABLE 3}

Granger Causality Tests

\begin{tabular}{|c|c|c|c|c|c|c|c|c|}
\hline & & & & & & Illiq & dity & \\
\hline & VOLB & VOLS & RETB & RETS & Stock & $\begin{array}{l}\text { Long- } \\
\text { Bond }\end{array}$ & $\begin{array}{c}\text { Medium- } \\
\text { Bond } \\
\end{array}$ & $\begin{array}{l}\text { Short- } \\
\text { Bond }\end{array}$ \\
\hline VOLB & & $\begin{array}{c}0.24 \\
(0.623)\end{array}$ & $\begin{array}{l}10.24 \\
(0.001)\end{array}$ & $\begin{array}{l}0.16 \\
(0.693)\end{array}$ & $\begin{array}{l}2.31 \\
(0.129)\end{array}$ & $\begin{array}{l}0.33 \\
(0.564)\end{array}$ & $\begin{array}{l}0.56 \\
(0.453)\end{array}$ & $\begin{array}{c}0.30 \\
(0.582)\end{array}$ \\
\hline VOLS & $\begin{array}{l}0.00 \\
(0.975)\end{array}$ & & $\begin{array}{l}0.54 \\
(0.464)\end{array}$ & $\begin{array}{l}2.47 \\
(0.116)\end{array}$ & $\begin{array}{l}3.05 \\
(0.081)\end{array}$ & $\begin{array}{c}0.12 \\
(0.723)\end{array}$ & $\begin{array}{l}0.80 \\
(0.371)\end{array}$ & $\begin{array}{l}4.06 \\
(0.044)\end{array}$ \\
\hline RETB & $\begin{array}{l}2.96 \\
(0.086)\end{array}$ & $\begin{array}{c}0.90 \\
(0.344)\end{array}$ & & $\begin{array}{l}8.53 \\
(0.004)\end{array}$ & $\begin{array}{l}1.62 \\
(0.204)\end{array}$ & $\begin{array}{l}5.83 \\
(0.016)\end{array}$ & $\begin{array}{l}0.53 \\
(0.465)\end{array}$ & $\begin{array}{l}27.56 \\
(<0.0001)\end{array}$ \\
\hline RETS & $\begin{array}{l}1.05 \\
(0.305)\end{array}$ & $\begin{array}{l}11.84 \\
(0.001)\end{array}$ & $\begin{array}{l}11.87 \\
(0.001)\end{array}$ & & $\begin{array}{l}72.17 \\
(<0.0001)\end{array}$ & $\begin{array}{l}0.87 \\
(0.351)\end{array}$ & $\begin{array}{l}0.76 \\
(0.382)\end{array}$ & $\begin{array}{l}8.95 \\
(0.003)\end{array}$ \\
\hline Illiquidity & & & & & & & & \\
\hline Stock & $\begin{array}{l}14.29 \\
(0.0002)\end{array}$ & $\begin{array}{l}0.27 \\
(0.600)\end{array}$ & $\begin{array}{l}0.86 \\
(0.354)\end{array}$ & $\begin{array}{c}0.81 \\
(0.369)\end{array}$ & & $\begin{array}{l}4.86 \\
(0.028)\end{array}$ & $\begin{array}{c}0.99 \\
(0.321)\end{array}$ & $\begin{array}{c}4.59 \\
(0.032)\end{array}$ \\
\hline Long-Bond & $\begin{array}{l}1.18 \\
(0.278)\end{array}$ & $\begin{array}{l}0.88 \\
(0.348)\end{array}$ & $\begin{array}{l}0.01 \\
(0.915)\end{array}$ & $\begin{array}{l}0.02 \\
(0.878)\end{array}$ & $\begin{array}{l}8.48 \\
(0.004)\end{array}$ & & $\begin{array}{l}0.15 \\
(0.701)\end{array}$ & $\begin{array}{l}0.01 \\
(0.929)\end{array}$ \\
\hline Medium-Bond & $\begin{array}{l}0.01 \\
(0.914)\end{array}$ & $\begin{array}{l}0.79 \\
(0.373)\end{array}$ & $\begin{array}{l}0.01 \\
(0.915)\end{array}$ & $\begin{array}{l}0.02 \\
(0.878)\end{array}$ & $\begin{array}{l}1.51 \\
(0.218)\end{array}$ & $\begin{array}{c}4.43 \\
(0.035)\end{array}$ & & $\begin{array}{l}7.08 \\
(0.008)\end{array}$ \\
\hline Short-Bond & $\begin{array}{c}0.02 \\
(0.884)\end{array}$ & $\begin{array}{l}1.10 \\
(0.293)\end{array}$ & $\begin{array}{l}0.26 \\
(0.611)\end{array}$ & $\begin{array}{l}1.19 \\
(0.276)\end{array}$ & $\begin{array}{l}8.54 \\
(0.004)\end{array}$ & $\begin{array}{l}11.12 \\
(0.0009)\end{array}$ & $\begin{array}{c}15.77 \\
(<0.0001)\end{array}$ & \\
\hline
\end{tabular}

The results for illiquidity across two markets are reported in the lower-right part of Table 3. There is a strong bidirectional causality. Amihud's (2002) illiquidity measure Granger causes both short- and long-term bond illiquidity. Shortand long-term bond illiquidity both Granger cause stock illiquidity. This indicates that illiquidity of one market is informative in predicting illiquidity of the other market. The results point toward a strong illiquidity linkage between stock and Treasury bond markets. Across bond maturities, short-term illiquidity Granger causes both medium- and long-term illiquidity, medium-term illiquidity Granger causes short- and long-term illiquidity, while long-term illiquidity has no causality effect over the other maturities.

The remainder of Table 3 presents the interaction of illiquidity with other endogenous variables. We find that stock volatility Granger causes stock illiquidity, and that the causality is in one direction only. This supports the arguments of Benston and Hagerman (1974), Ho and Stoll (1983), and O'Hara and Oldfield (1986) that volatility affects illiquidity by altering the inventory risk borne by market makers. Stock returns have a causal relationship with stock illiquidity. Bond returns cause long- and short-term bond illiquidity, but the reverse is not true. 
Across markets, stock returns cause short-term bond illiquidity. Stock volatility Granger causes short-term bond illiquidity, and bond volatility has no effect on stock illiquidity. Stock illiquidity Granger causes bond volatility. Overall, not only is there a strong causality between illiquidity of stock and bond markets, but there is also significant cross-market dynamics between returns, volatility, and illiquidity.

Note that the Granger causality results are based on the analysis of the coefficients from a single equation and do not account for the joint dynamics implied by the VAR system. A clearer picture can potentially emerge by the use of impulse response functions (IRFs). The IRF traces the impact of a one-time, unit standard deviation, positive shock to one variable on the current and future values of the endogenous variables. Since innovations are correlated, they need to be orthogonalized. They are computed using standard Cholesky decompositions of the VAR residuals and assuming that innovations in the variables placed earlier in the VAR have greater effects on the following variables. Thus, one approach is to order the variables according to the order in which they influence the other variables. Relying on the prior evidence (CSS (2005)), we order our variables as follows: VOLB, VOLS, RETB, RETS, Stock Illiquidity, Long-Bond Illiquidity, Medium-Bond Illiquidity, and Short-Bond Illiquidity. The conclusions about IRFs are insensitive to the ordering of stock and bond illiquidity. In fact, our estimates gain even stronger statistical power if we put stock illiquidity at the end of VAR ordering.

Graph A of Figure 1 illustrates the response of the stock illiquidity to a unit standard deviation change in a particular variable, traced forward over a period of 24 months. In the figures, month 0 gives the contemporaneous impact and months $1-24$ plot the effect from +1 to +24 months. Bootstrap $95 \%$ confidence bands are provided to gauge the statistical significance of the responses. The figure indicates that stock illiquidity increases by 0.11 standard deviation units contemporaneously in response to its own shock, with the response decaying rapidly from month to month. An innovation in stock returns results in a reduction in stock illiquidity, while a shock to stock volatility predicts an increase in the stock illiquidity. These results are consistent with those of CRS (2001), which show that up-market moves have a positive effect on liquidity, and with models of microstructure, which argue that increased volatility, by increasing inventory risk, tends to increase stock market illiquidity. Besides stock returns, bond returns also forecast a reduction in stock illiquidity.

There is evidence of cross-market illiquidity dynamics in Figure 1. In particular, stock illiquidity increases in response to positive shocks in short- and longterm bond illiquidity. Medium-term illiquidity has an opposite short-lasting effect on stock illiquidity. The effect of bond illiquidity on stock illiquidity is more pronounced, stronger, and longer-lasting for short-term bonds. This evidence highlights the importance of analyzing bond illiquidity of different maturities in cross-market studies and also brings attention to the illiquidity of short-term bonds. The behavior of short-term bond illiquidity is discussed in more detail later.

Graphs B, C, and D of Figure 1 illustrate the responses of long-, medium-, and short-term bond illiquidity, accordingly, to the unit shocks in the endogenous variables. Similar to the stock market, stock and bond market returns forecast 
FIGURE 1

\section{Response to Endogenous Variables}

Response to Cholesky one standard deviation. Dashed lines represent bootstrap 95\% confidence bands derived via 1,000 bootstrap simulations.

Graph A. Response of Stock Illiquidity to Endogenous Variables
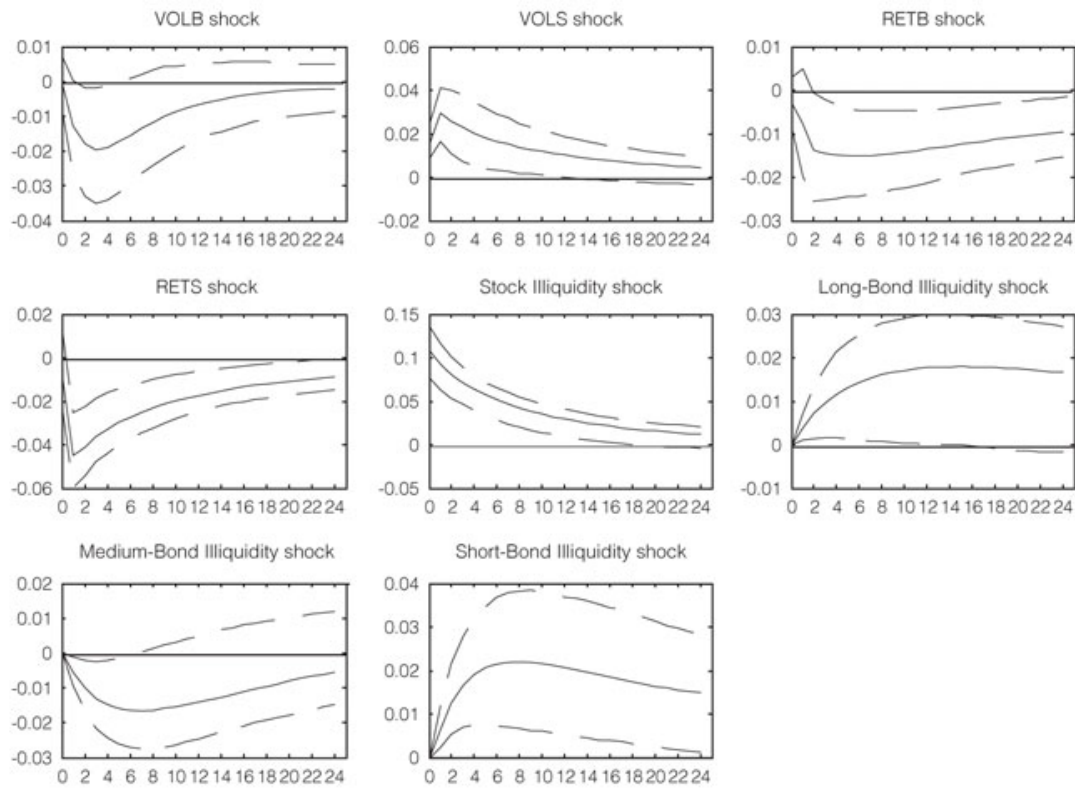

Graph B. Response of Long-Bond Illiquidity to Endogenous Variables
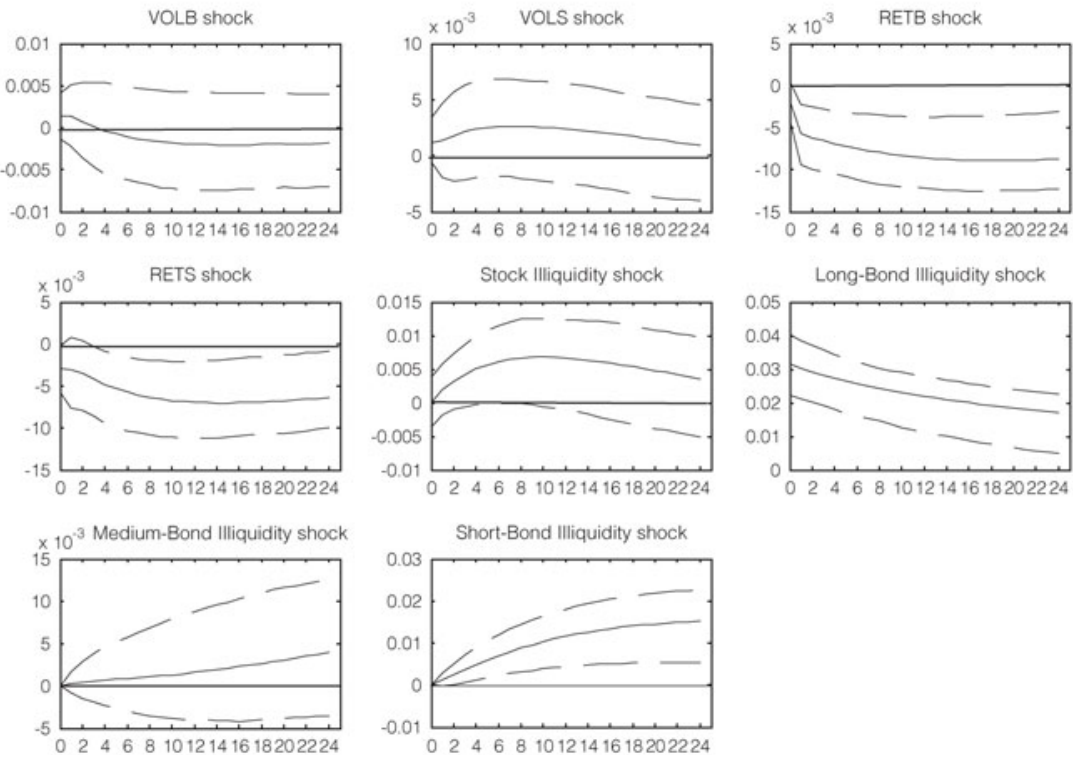
FIGURE 1 (continued)

\section{Response to Endogenous Variables}

Graph C. Response of Medium-Bond IIiquidity to Endogenous Variables
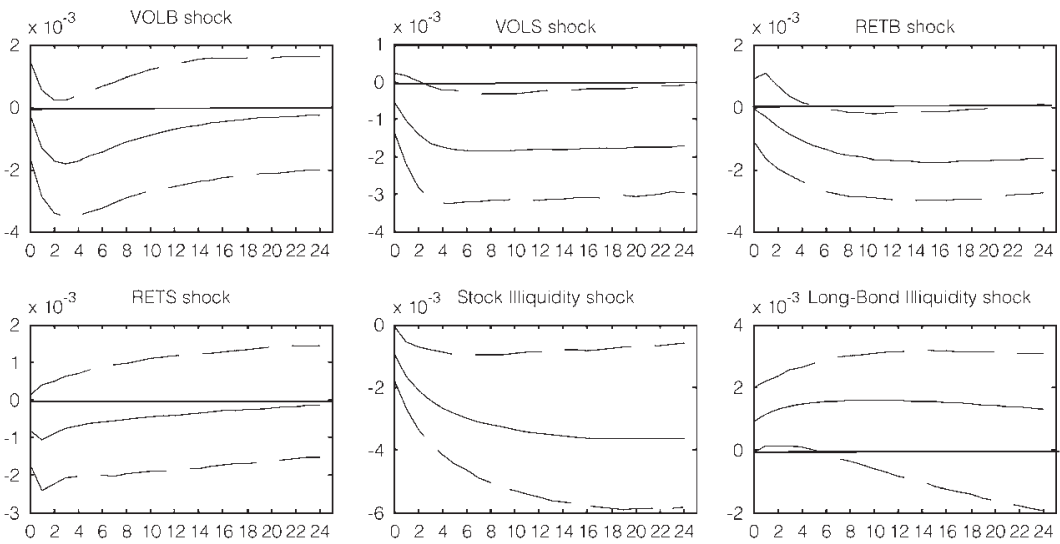

024681012141618202224
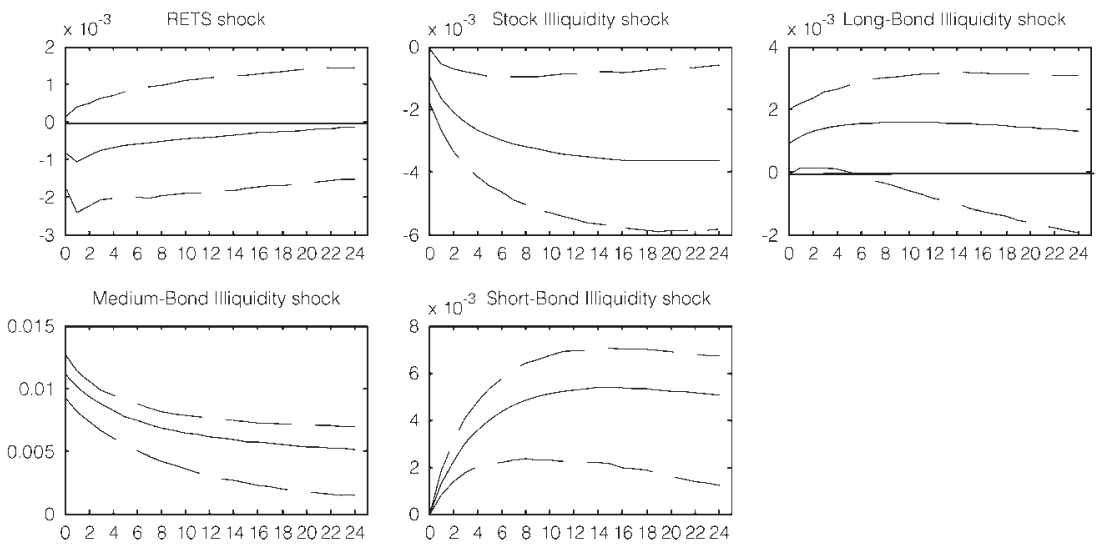

Graph D. Response of Short-Bond Illiquidity to Endogenous Variables
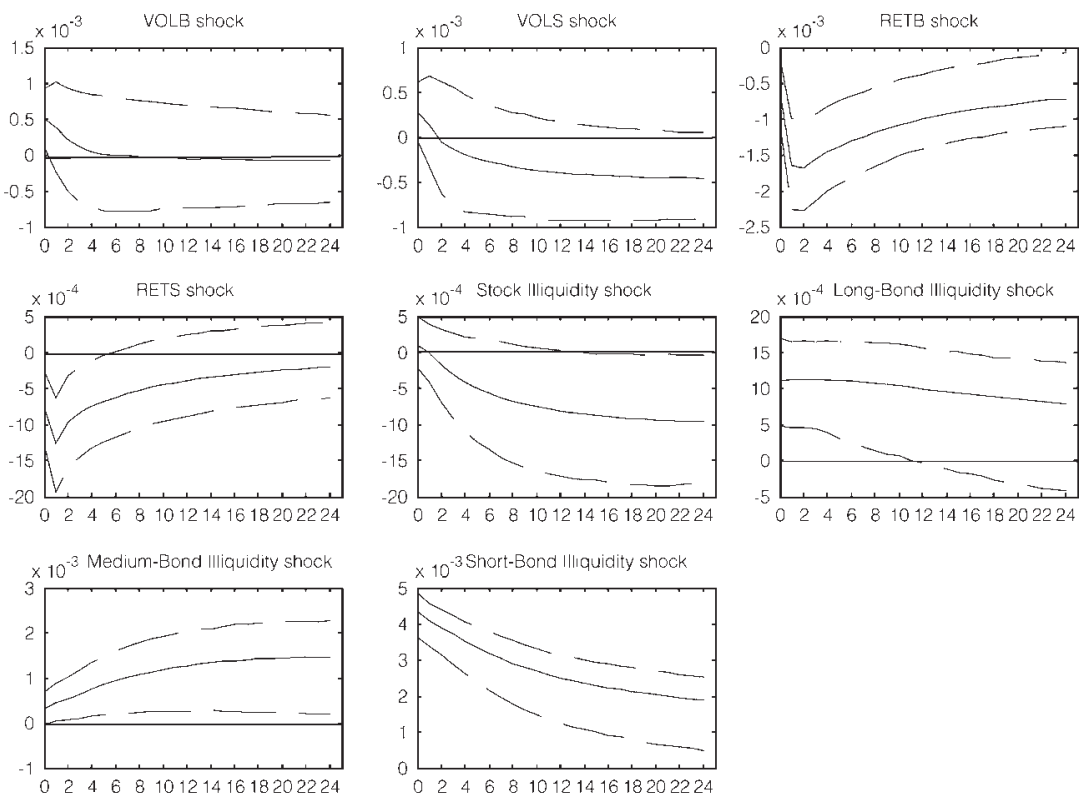
reductions in bond illiquidity. ${ }^{11}$ Therefore, up-market moves in equities improve not only stock liquidity (CRS (2001)) but bond liquidity as well. Similarly, up-market moves in the bond market improve liquidity of both stocks and bonds. ${ }^{12}$ This is consistent with the view that price changes in one market can trigger changes in investor expectations and in optimal portfolio composition. This can lead to a wave of trading in both markets, which would eventually affect stock and bond illiquidity. This intuition is consistent with the results of the fundflows literature (Goetzmann and Massa (2002), Longstaff (2004), and Agnew and Balduzzi (2005)).

The results for bond illiquidity (Graphs B, C, and D of Figure 1) reflect crossmarket illiquidity dynamics. A positive shock to stock illiquidity is associated with a persistent decrease in medium- and short-term bond illiquidity, while this effect is insignificant for long-term bonds. This result is consistent with flight-toquality and flight-to-liquidity episodes (Longstaff (2004)). Bond market illiquidity tends to comove: A positive illiquidity shock in one maturity-type is associated with illiquidity movement in the same direction across the other maturities.

Overall, we demonstrate that illiquidity of one market has predictive power over illiquidity of the other market. This establishes illiquidity linkage between the two asset classes. We also find that this effect is more pronounced for shortterm bond illiquidity, which, in turn, highlights the importance of studying bond illiquidity across different maturity categories.

\section{B. VAR Estimation Results: Macroeconomic Variables}

We now estimate the effect of monetary policy on stock and bond illiquidity. The recent search for an appropriate measure of the impact of monetary policy has evolved along two well-worn paths: interest rates and monetary aggregates. Therefore, as indicators of the monetary policy stance, we include the federal funds rate (FED), following Bernanke and Blinder (1992), and "orthogonalized" nonborrowed reserves (NBRX), based on Strongin (1995). Strongin (1995) argues that innovations in the mix of borrowed and nonborrowed reserves should be used to capture true monetary policy disturbances. To construct the NBRX measure, we follow Strongin (1995) and Patelis (1997) and first normalize the NBR (defined as NBR plus extended credit (ECR)) and TR series by a 36-month moving average of TR. The residuals from a regression of normalized NBR on normalized TR are then collected to form the NBRX series. We associate lower values of this variable with increased monetary tightness.

Among other macroeconomic variables, we use the growth rate of industrial production (IP) and inflation (the growth rates of the consumer price index (CPI)).

The monthly data on IP, CPI, FED, NBR, TR, and ECR are from the Federal Reserve Bank of St. Louis. The series on IP, CPI, NBR, and TR are seasonally

\footnotetext{
${ }^{11}$ The exception is medium-term bond illiquidity, where the effect of stock returns is insignificant.

${ }^{12}$ While CRS (2001) show that returns have impact on liquidity within the equity market, we contribute by finding that returns have impact across markets.
} 
adjusted, and the growth rates of relevant variables are given by their first log differences. Since the unit root test indicates nonstationarity in FED, the subsequent analysis uses first differences. In accordance with the AIC and Schwarz Bayesian Information Criterion, we estimate VAR with one lag.

In the initial VAR, IP, CPI, FED, and NBRX are placed first in the ordering, with ordering of the other variables kept the same as in the previous section. The motivation here is that, while financial markets respond to monetary policy, the latter is relatively exogenous to the financial system. There are precedents for putting monetary policy instruments before financial variables in the VAR ordering (Thorbecke (1997), CSS (2005)). Later, as in CSS, we allow for the fact that during crisis periods, monetary policy may specifically respond to conditions in the financial markets. The ordering of macroeconomic variables (IP, CPI, FED, and NBRX) is based on conventional practice in the macroeconomic literature.

The Granger causality results reported in Table 4 indicate that shocks to CPI, FED, and NBRX are informative in predicting stock illiquidity. Shocks to CPI are informative in predicting bond illiquidity across all maturities, shocks to FED affect illiquidity of medium- and short-term bonds, and NBRX predicts shortterm bond illiquidity only. Thus, there is evidence that macroeconomic variables are linked to financial market illiquidity.

TABLE 4

Granger Causality Tests: Macroeconomic Variables

Table 4 presents $\chi^{2}$ statistics and $p$-values (row (2)) of pair-wise Granger causality tests between endogenous VAR variables. Null hypothesis is that row variable does not Granger cause column variable. Bond illiquidity estimates are based on quoted spreads across bonds of three types of maturities: short (with maturity less than or equal to one year), medium (with maturity between two and seven years), and long (with 10 years to maturity). Stock illiquidity is measured with Amihud's (2002) illiquidity measure. RET is the market return and VOL is the return volatility computed as standard deviation of daily returns over each month. The returns used are the 10-year Treasury note return from CRSP Fixed Term indices file for bonds and the CRSP value-weighted index return for stocks. The suffixes B and S refer to bond and stock variables, respectively. IP is industrial production growth, CPI is the CPI inflation, FED is change in the federal funds rate, and NBRX is the orthogonalized nonborrowed reserves. The sample spans the period from July 1962 to December 2003 (498 months).

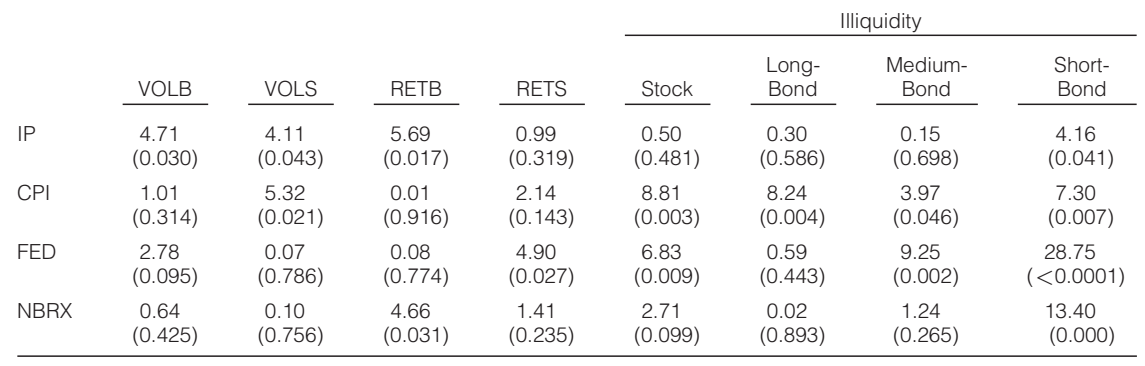

Graph A of Figure 2 presents the impulse response functions of stock illiquidity to macroeconomic variables. We find that stock illiquidity is positively associated with a positive shock to FED and decreases in response to positive shock to NBRX. While the effect of NBRX on stock illiquidity begins with a lag of six months, the effect of FED begins with the lag of one month and displays persistence. This suggests that tightening of monetary policy forecasts an increase in stock market illiquidity. 
FIGURE 2

\section{Response to Macroeconomic Variables}

Response to Cholesky one standard deviation. Dashed lines represent bootstrap 95\% confidence bands derived via 1,000 bootstrap simulations.

Graph A. Response of Stock Illiquidity to Macroeconomic Variables
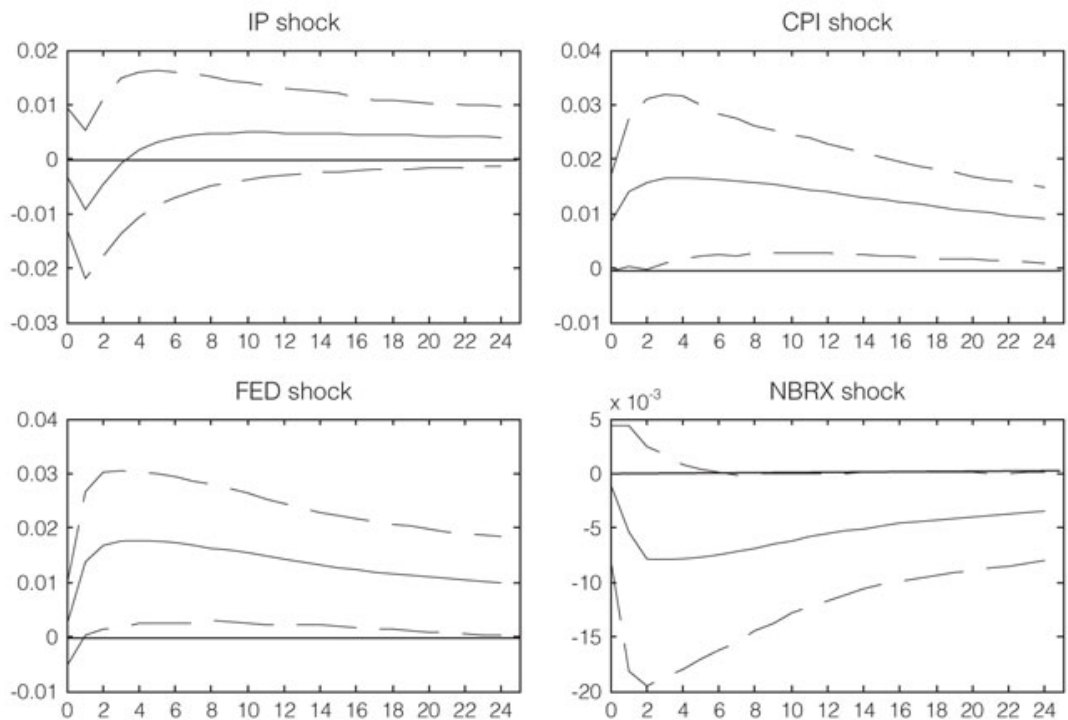

Graph B. Response of Long-Bond Illiquidity to Macroeconomic Variables
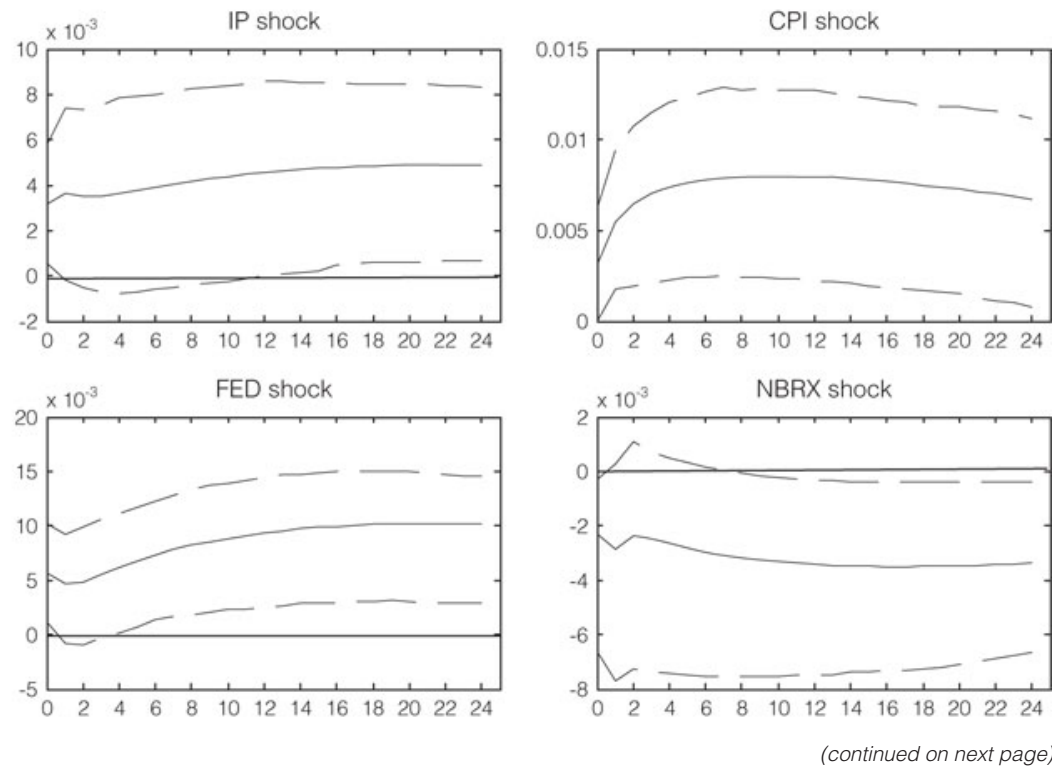
FIGURE 2 (continued)

\section{Response to Macroeconomic Variables}

Graph C. Response of Medium-Bond Illiquidity to Macroeconomic Variables
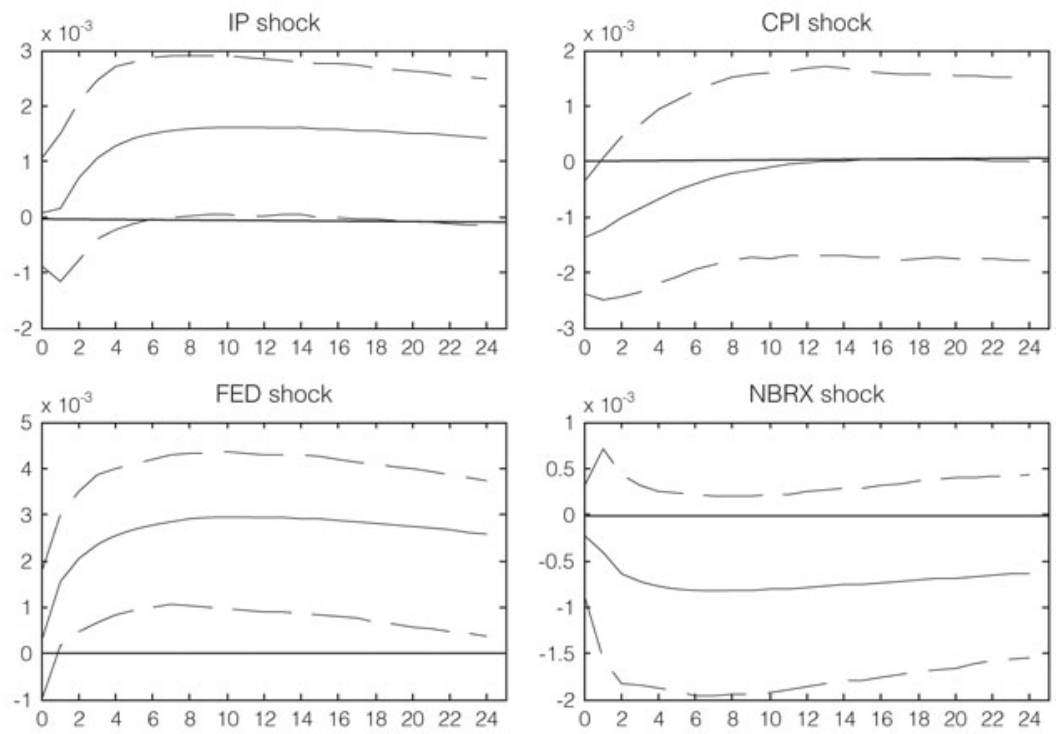

Graph D. Response of Short-Bond Illiquidity to Macroeconomic Variables
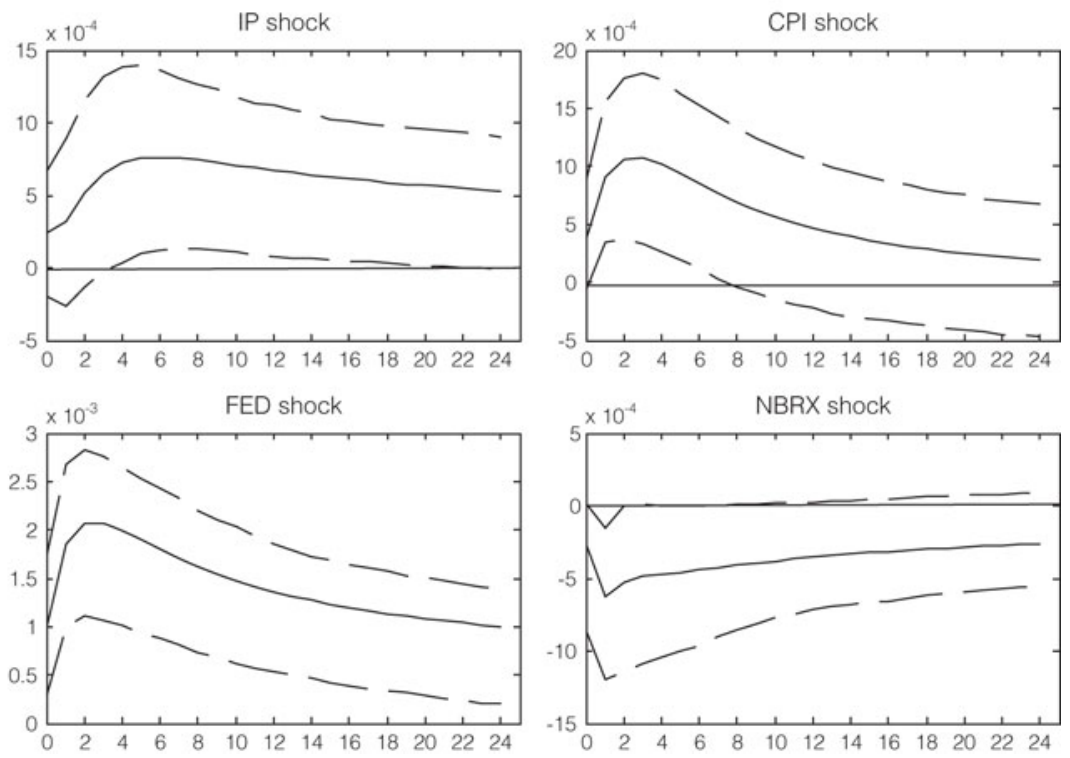

Innovations in CPI positively and significantly affect stock illiquidity, which indicates that an increase in inventory-holding and order-processing costs due to inflation are reflected in higher transaction costs. IP is not informative in predicting stock illiquidity. 
Qualitatively similar results are observed for bond illiquidity across different maturities and are reported in Graphs B, C, and D of Figure 2. A positive shock to FED causes an increase in bond illiquidity across all maturities. However, a shock to FED impacts illiquidity of different maturity bonds differently. It affects illiquidity of short-term bonds immediately. For medium-term bonds, the effect becomes significant after a short lag of one month. For long-term bonds, the effect becomes significant after a longer lag of four months. A FED shock is persistent and lasts for a long time for all three maturity classes.

An increase in NBRX has different impacts on illiquidity of different maturity bonds. A shock to NBRX affects illiquidity of short-term bonds after one month, and the effect remains significant for approximately seven months. A shock to NBRX also affects illiquidity of long-term bonds. The effect becomes significant after a lag of eight months and remains significant longer than for short-term bonds. The effect of NBRX shock on illiquidity of medium-term bonds is not statistically significant, but the direction of the effect is the same as for the short- and long-term bonds.

Shocks to FED and NBRX both have an impact on bond market illiquidity. The results suggest that, as for the stock market, tightening of monetary policy forecasts an increase in bond market illiquidity. This effect is especially pronounced for short-term bonds, which, when compared to the other maturity categories, are first to respond to a shock in FED or NBRX.

A shock to CPI significantly increases illiquidity of long- and short-term bonds and lasts for longer in longer-term bonds. A shock to IP does not seem to be an important immediate driver of illiquidity. It increases short-term illiquidity with a lag of four months and with longer lags for the two other maturities. The lag is the longest for the long-maturity bonds. Positive productivity shocks can be related to higher economic activity (McQueen and Roley (1993)) when risky assets are more attractive investments (Eisfeldt (2004)). This might cause cash outflow with a lag from the riskless assets and subsequently increase their illiquidity.

Overall, we find that macroeconomic variables have the most immediate effect on the illiquidity of short-term bonds when compared to the illiquidity of medium or long-term bonds. The impact of macroeconomic variables is stronger for short- and long-term bonds than for medium-term bonds. This suggests a distinctive role of short- and long-term illiquidity in capturing monetary policy effects in the bond market.

To allow for the fact that the Federal Reserve may respond to financial markets, we re-estimate the VAR with an alternative ordering. To determine the new ordering, we first investigate the relationship between FED and NBRX and illiquidity by placing the monetary variables (FED and NBRX) at the end of the ordering. When we do this, we find little evidence that FED and NBRX respond to illiquidity shocks of either market. Thus, we place monetary policy variables before illiquidity. ${ }^{13}$ When FED and NBRX are placed at the end of the ordering, we find that these variables respond to the shocks in returns of either market, consistent with intuition and findings in the previous literature (CSS (2005)).

\footnotetext{
${ }^{13} \mathrm{We}$ are grateful to the referee for this suggestion. These results are not reported for brevity and are available from the authors.
} 
We therefore put the monetary policy variables after market returns in the new VAR ordering. Our alternative VAR ordering becomes: IP, CPI, VOLB, VOLS, RETB, RETS, NBRX, FED, Stock Illiquidity, Long-Bond Illiquidity, MediumBond Illiquidity, and Short-Bond Illiquidity.

Figure 3 presents the impulse response graphs for the new ordering. Graph A illustrates that under the new ordering, illiquidity of medium- and short-term bonds continues to respond significantly and positively to shocks in FED. These results are virtually unchanged when compared to the initial ordering. Illiquidity of long-term bonds responds with a longer lag to the shock in FED compared to the initial ordering (Graph B of Figure 2). Stock illiquidity, when compared to the initial ordering (Graph A of Figure 2), now responds with a lag of six months to FED, and this effect is somewhat less persistent that under the initial ordering.

NBRX continues to affect stock illiquidity with a lag (Graph B of Figure 3), and the effect is similar to the initial ordering. The effect of NBRX shock on bond illiquidity appears to be stronger than under the initial ordering for all maturities. Taken together, the results suggest that the monetary policy effect (FED and NBRX) on illiquidity is generally robust to model specification.

Overall, our results point to a connection between macroeconomic variables and illiquidity conditions in the stock and bond markets. Generally, a shock to macroeconomic variables first affects illiquidity of short-term bonds. However, we observe an impact of macroeconomic variables on the illiquidity of bonds of all three maturity classes and on the illiquidity of the stock market. When we place the monetary variables first in the ordering (based on the idea that monetary policy targets the macroeconomy and is largely exogenous to financial market variables), our impulse response analyses suggest that monetary tightening forecasts increases in stock and bond market illiquidity. For our sample period, shocks to the federal funds rate are associated with illiquidity as conjectured: An increase in the federal funds rate is associated with an increase in spreads, while a decrease has the opposite effect. The results of our impulse response analysis remain largely unchanged under the new ordering when the monetary variables are placed after the financial market variables in the VAR ordering. A shock to FED affects stock illiquidity with a somewhat longer lag under the new ordering. Below we explore the relationship between shocks to monetary variables and illiquidity of the bond and stock markets in more detail.

\section{Monetary Shocks and Stock Market Illiquidity}

Monetary policy may affect stock illiquidity both directly and indirectly. Granger causality tests (Table 4) suggest that FED and NBRX affect stock illiquidity. There may also be an important indirect effect, which works through bond illiquidity. Our prior results indicate the presence of a lead-lag relationship between stock and bond illiquidity, and that positive shocks to bond illiquidity increase stock illiquidity. Monetary policy affects bond illiquidity, and the effect is robust to the VAR ordering. ${ }^{14}$ Illiquidity in the bond market increases when

\footnotetext{
${ }^{14}$ This is consistent with the findings in the previous literature that Treasury quoted spreads increase in response to macroeconomic news (Fleming and Remolona (1997), (1999), Balduzzi et al. (2001), and Green (2004)). This suggests that illiquidity of bonds picks up a macroeconomic factor.
} 


\section{FIGURE 3}

\section{Response of Stock and Bond Market Illiquidity}

Response to Cholesky one standard deviation. Dashed lines represent bootstrap 95\% confidence bands derived via 1,000 bootstrap simulations.

Graph A. Response of Stock and Bond Market Iliquidity to FED under Alternative VAR Ordering: IP, CPI, VOLB, VOLS, RETB, RETS, NBRX, FED, Stock Iliquidity, Long-Bond, Medium-Bond, and Short-Bond Iliquidity
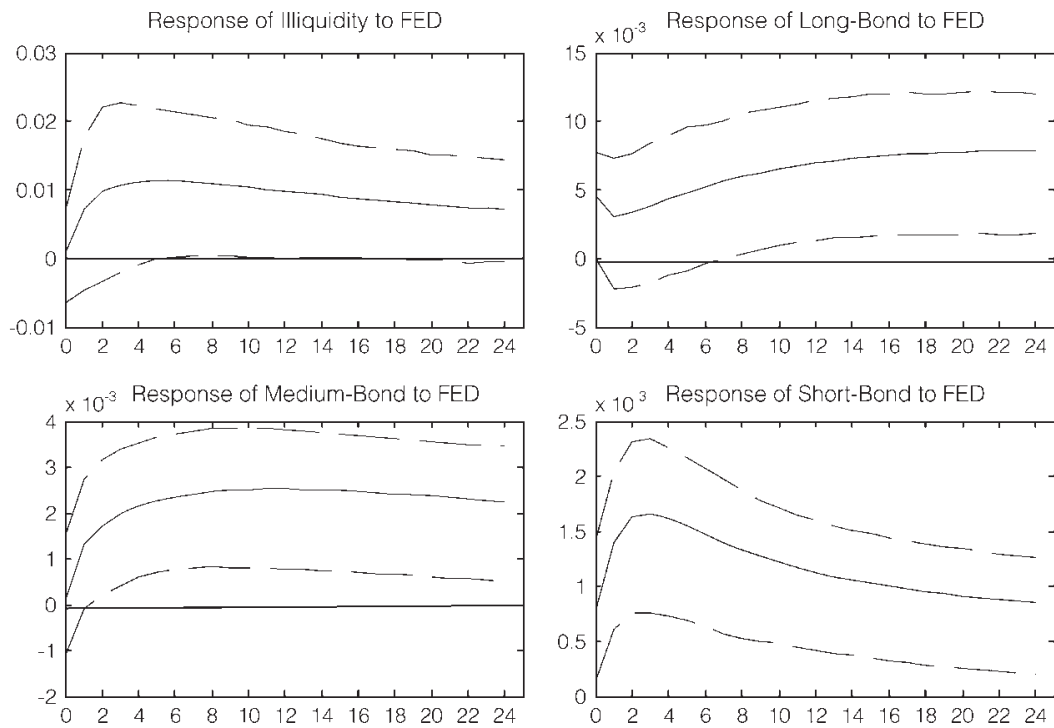

Graph B. Response of Stock and Bond Market Iliquidity to NBRX under Alternative VAR Ordering: IP: CPI, VOLB, VOLS, RETB, RETS, NBRX, FED, Stock Illiquidity; Long-Bond Illiquidity, Medium-Bond IIiquidity, and Short-Bond Illiquidity
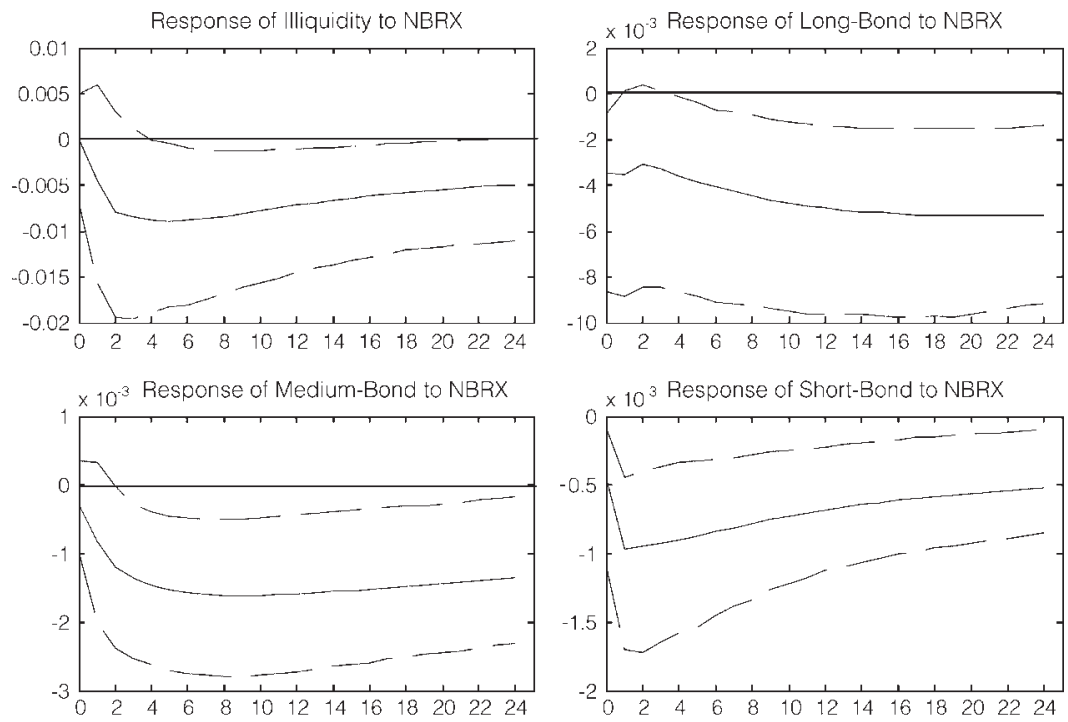
monetary policy is tightened. These results taken together suggest that bond illiquidity can first become affected by monetary policy variables, and that bond illiquidity can subsequently transmit these shocks into the stock market by increasing stock market illiquidity. The net effect of monetary policy on stock illiquidity, therefore, consists of the direct effect, the indirect effect of monetary policy on bond illiquidity, and, subsequently, of the bond illiquidity on stock illiquidity. Bond illiquidity, therefore, can act as a channel that transmits monetary policy shocks into the stock market illiquidity.

To study the indirect channel we re-estimate VAR (with the initial ordering) with the restriction that the coefficients for FED and NBRX in the equation for stock illiquidity are zero. This precludes any direct effect of FED and NBRX on stock illiquidity but leaves the indirect channel intact, which allows us to study the importance of bond market illiquidity for transmitting monetary shocks into the stock market. Figure 4 reports impulse response functions (IRFs).

\section{FIGURE 4}

Indirect Effect: Response of Stock Illiquidity to Monetary Policy Variables, Restricted VAR with Initial Ordering: IP, CPI, FED, NBRX, VOLB, VOLS, RETB, RETS, Stock Illiquidity, Long-Bond Illiquidity, Medium-Bond Illiquidity, and Short-Bond Illiquidity

Response to Cholesky one standard deviation. Dashed lines represent bootstrap 95\% confidence bands derived via 1,000 bootstrap simulations.
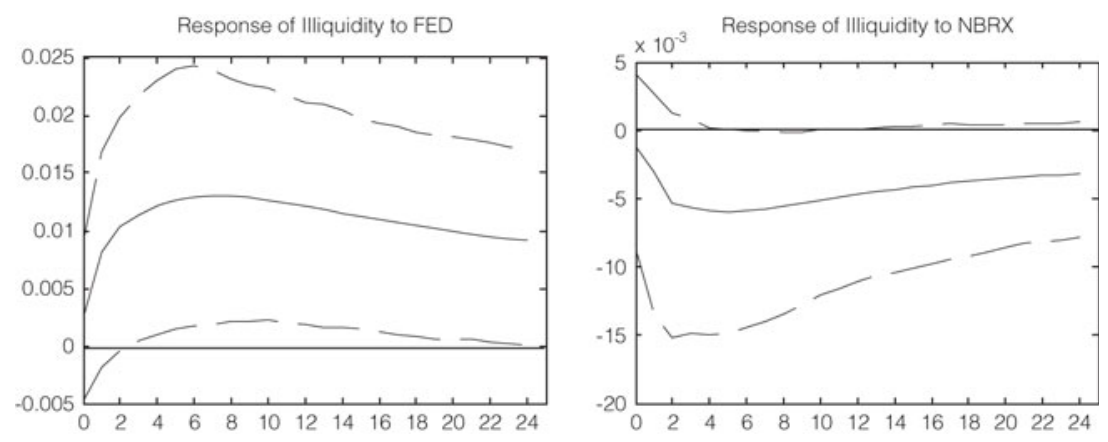

We find that stock illiquidity reacts positively to a tightening of monetary policy, but with a lag. A shock to FED results in a response in stock illiquidity that is significant, beginning with a lag of three months. The effect of FED on stock illiquidity in the restricted VAR is explained by the indirect effect through bond illiquidity. This shows the transmission of monetary shock through the indirect channel. When both the direct and indirect channels are at work (Graph A of Figure 2) the effect takes place at a lag of one month. Comparing the magnitude of direct and indirect effects shows that most of the effect of FED on stock illiquidity comes from the indirect impact. For robustness, we restrict VAR even further by placing the restriction that the coefficients for VOLB, VOLS, RETB, and RETS (in addition to FED and NBRX) in the equation for stock illiquidity are zero. We find that the effect of FED on stock illiquidity in this restricted VAR is the same as reported in Figure 4.

A shock to NBRX results in a response in stock illiquidity that is significant, beginning with the lag of six months. The similarity in IRFs for the effect 
of NBRX on stock illiquidity in Graph A of Figure 2 (unrestricted) and Figure 4 (restricted) indicates that most of the effect of NBRX on stock illiquidity is indirect and that bond illiquidity acts as a transmission channel.

We also reestimate VAR with the restriction that the coefficients for FED and NBRX in the equation for short-bond illiquidity are zero. This precludes any indirect effect of FED and NBRX on stock illiquidity via illiquidity of short-term bonds. Under this restriction, the effect of FED and NBRX on stock illiquidity is no longer significant. This confirms the importance of the indirect effect in the impact of monetary policy on stock illiquidity.

The results from the restricted VAR show that the effect of monetary policy on stock illiquidity is preserved when bond illiquidity is the indirect transmission channel. Monetary policy has a quick and significant impact on bond illiquidity. A shock to the bond illiquidity, in turn, has an effect on the stock illiquidity. The evidence taken together suggests that bond illiquidity acts as a channel that transmits monetary policy shocks into the stock market illiquidity.

\section{Conclusion}

We examine the joint behavior of stock and bond market illiquidity over a long time period from July 1962 to December 2003. This analysis yields three main messages. First, stock and Treasury bond markets are integrated via illiquidity. There is a lead-lag relationship between the illiquidity of two markets and bidirectional Granger causality. A change in the illiquidity of one market affects illiquidity conditions in the other. The effect of stock illiquidity on bond illiquidity is consistent with flight-to-quality and flight-to-liquidity episodes.

Second, while stock and bond market illiquidity share many similarities (and reflect the ability to buy or sell large quantities of an asset quickly and at low cost), they have different economic natures. Bond illiquidity is quick to capture the effect of monetary policy variables, while this effect may take longer for stock illiquidity. Our results are consistent with the view that monetary policy shocks are reflected in bond illiquidity and then channeled into the equity market via the effect of bond illiquidity on stock illiquidity. This establishes a link between monetary policy and financial markets illiquidity. Generally, illiquidity increases due to the tightening of monetary policy.

Third, this study brings attention to the importance of studying bond illiquidity of different maturities. In particular, our results indicate that while illiquidity across maturities tends to comove, illiquidity of short-term bonds is more sensitive to monetary policy shocks and has a stronger effect on stock market illiquidity compared to medium- and long-term bonds. Therefore, in an informational sense, the illiquidity of short-term bonds plays a significant role in cross-market dynamics.

\section{References}

Agnew, J., and P. Balduzzi. "Rebalancing Activity in 401(k) Plans." Working Paper, Boston College (2005).

Amihud, Y. "Illiquidity and Stock Returns: Cross-Section and Time-Series Effects." Journal of Financial Markets, 5 (2002), 31-56. 
Amihud, Y., and H. Mendelson. "Asset Pricing and the Bid-Ask Spread." Journal of Financial Economics, 17 (1986), 223-249.

Amihud, Y., and H. Mendelson. "The Effect of Beta, Bid-Ask Spread, Residual Risk, and Size on Stock Returns.” Journal of Finance, 44 (1989), 479-486.

Amihud, Y., and H. Mendelson. "Liquidity, Maturity, and the Yields on U.S. Treasury Securities." Journal of Finance, 46 (1991), 1411-1425.

Balduzzi, P.; E. Elton; and T. Green. "Economic News and Bond Prices: Evidence from U.S. Treasury Market." Journal of Financial and Quantitative Analysis, 36 (2001), 523-543.

Beber, A.; M. Brandt; and K. Kavajecz. "Flight-to-Quality or Flight-to-Liquidity? Evidence from the Euro-Area Bond Market.” Review of Financial Studies, 22 (2009), 925-957.

Benston, G., and R. Hagerman. "Determinants of Bid-Ask Spreads in the Over-the-Counter Market." Journal of Financial Economics, 1 (1974), 353-364.

Bernanke, B., and A. Blinder. "The Federal Funds Rate and the Channels of Monetary Transmission." American Economic Review, 82 (1992), 901-921.

Boudoukh, J., and R. Whitelaw. "Liquidity as a Choice Variable: A Lesson from Japanese Government Bond Market." Review of Financial Studies, 6 (1993), 265-292.

Brandt, M. W., and K. A. Kavajecz. "Price Discovery in the U.S. Treasury Market: The Impact of Orderflow and Liquidity on the Yield Curve." Journal of Finance, 59 (2004), 2623-2654.

Brennan, M., and A. Subrahmanyam. "Market Microstructure and Asset Pricing: On the Compensation for Illiquidity in Stock Returns." Journal of Financial Economics, 41 (1996), 441-464.

Chordia, T.; A. Sarkar; and A. Subrahmanyam. "An Empirical Analysis of Stock and Bond Market Liquidity.” Review of Financial Studies, 18 (2005), 85-129.

Chordia, T.; R. Roll; and A. Subrahmanyam. "Commonality in Liquidity." Journal of Financial Economics, 56 (2000), 3-28.

Chordia, T.; R. Roll; and A. Subrahmanyam. "Market Liquidity and Trading Activity." Journal of Finance, 56 (2001), 501-530.

Eisfeldt, A. "Endogenous Liquidity in Asset Markets." Journal of Finance, 59 (2004), 1-30.

Fleming, J.; C. Kirby; and B. Ostdiek. "Information and Volatility Linkages in the Stock, Bond, and Money Markets.” Journal of Financial Economics, 49 (1998), 111-137.

Fleming, M. “Measuring Treasury Market Liquidity.” Economic Policy Review, 9 (2003), 83-108.

Fleming, M., and E. Remolona. "What Moves the Bond Market?" Economic Policy Review, 3 (1997), 31-50.

Fleming, M., and E. Remolona. "Price Formation and Liquidity in the U.S. Treasury Market: The Response to Public Information.” Journal of Finance, 54 (1999), 1901-1915.

Fox, S. "Assessing TAA Manager Performance." Journal of Portfolio Management, 26 (1999), 40-49.

Goetzmann, W., and M. Massa. "Daily Momentum and Contrarian Behavior of Index Fund Investors." Journal of Financial and Quantitative Analysis, 37 (2002), 375-389.

Goldreich, D.; B. Hanke; and P. Nath. "The Price of Future Liquidity: Time-Varying Liquidity in the U.S. Treasury Market.” Review of Finance, 9 (2005), 1-32.

Green, C. T. "Economic News and the Impact of Trading on Bond Prices." Journal of Finance, 59 (2004), 1201-1234.

Hasbrouck, J. "Trading Costs and Returns for U.S. Equities: The Evidence from Daily Data.” Working Paper, New York University (2006).

Hasbrouck, J., and D. Seppi. "Common Factors in Prices, Order Flows, and Liquidity." Journal of Financial Economics, 59 (2001), 383-411.

Harvey, C., and R. Huang. "The Impact of Federal Reserve Bank's Open Market Operations.” Journal of Financial Markets, 5 (2002), 223-257.

Ho, T., and H. Stoll. “The Dynamics of Dealer Markets under Competition.” Journal of Finance, 38 (1983), 1053-1074.

Huang, R.; J. Cai; and X. Wang. "Information-Based Trading in the Treasury Note Interdealer Broker Market.” Journal of Financial Intermediation, 11 (2002), 269-296.

Huberman, G., and D. Halka. "Systematic Liquidity." Journal of Financial Research, 2 (2001), $161-178$.

Ingersoll, J. E., Jr. Theory of Financial Decision Making. Savage, MD: Rowman and Littlefield (1987).

Jones, C. "A Century of Stock Market Liquidity and Trading Costs.” Working Paper, Columbia University (2002).

Kamara, A. "Liquidity, Taxes, and Short-Term Treasury Yields." Journal of Financial and Quantitative Analysis, 29 (1994), 403-417.

Krishnamurthy, A. "The Bond/Old-Bond Spread." Journal of Financial Economics, 66 (2002), $463-506$. 
Longstaff, F. A. “The Flight-to-Liquidity Premium in U.S. Treasury Bond Prices.” Journal of Business, 77 (2004), 511-526.

McQueen, G., and V. Roley. "Stock Prices, News, and Business Conditions." Review of Financial Studies, 6 (1993), 683-707.

O'Hara, M., and G. Oldfield. "The Microeconomics of Market Making." Journal of Financial and Quantitative Analysis, 21 (1986), 361-376.

Pastor, L., and R. Stambaugh. "Liquidity Risk and Expected Stock Returns.” Journal of Political Economy, 113 (2003), 642-685.

Patelis, A. "Stock Return Predictability and the Role of Monetary Policy." Journal of Finance, 52 (1997), 1951-1972.

Shiller, R. J. Market Volatility. Cambridge, MA: MIT Press (1989).

Shiller, R. J., and P. Perron. "Testing the Random Walk Hypothesis: Power vs. Frequency of Observation." Economics Letters, 18 (1985), 381-386.

Strongin, S. "The Identification of Monetary Policy Disturbances: Explaining the Liquidity Puzzle." Journal of Monetary Economics, 35 (1995), 463-497.

Swensen, D. Pioneering Portfolio Management: An Unconventional Approach to Institutional Investment. New York, NY: Free Press (2000).

Thorbecke, W. "On the Stock Market Returns and Monetary Policy." Journal of Finance, 52 (1997), 635-654.

Warga, A. "Bond Return, Liquidity, and Missing Data." Journal of Financial and Quantitative Analysis, 27 (1992), 605-617.

Xiao, Z., and P. Phillips. "Efficient Detrending in Cointegrating Regression." Econometric Theory, 15 (1999), 519-548. 